\title{
Classification of Public Signs and Their Characteristics
}

\author{
Yiqiu Yang \\ English Department, Qingdao University of Science \& Technology \\ Middle Section of Songling Road, Qingdao 266061, China \\ Tel: 86-532-8895-6956Ｅ-mail: luciateacher@163.com
}

\begin{abstract}
Public signs play a very important role in the life and work of he public, which facilitate the communication of people of different nation. Public signs have their own stylistic characteristics. This paper tries to analyze the linguistic features of English public sign expressions, aiming to classify them into different categories.
\end{abstract}

Keywords: Public signs, Characteristics, Classification

\section{Introduction}

It is well accepted that the translation of public signs is an indispensable part of communication materials. According to Duan Liancheng (1988), there are two kinds of materials: ordinary materials and formal materials. Ordinary materials aim to promote culture, including materials on politics, economy, society, culture and history, people's life, scenic spots and historic sites. Formal materials refer to official documents, formal talks and works of high-ranking officials, diplomatic talks, economic and trade contracts, legal instruments as well as scientific and technological exchange information.

In the process of the world-wide exchange, a systematic study on public signs and their translation will, no doubt, contribute a lot to the development of communication materials translation.

Public signs, from different perspectives, can be classified into different catalogues. From the perspective of material of which the sign is made, it can be classified as traditional signs (which are made of metal, paper, wood or directly written on walls) and non-traditional (or electronic, digital) ones; from the perspective of writing, they can be classified as that displayed in marks, pictures, words or the combination of these forms; from the perspective of function, they can be divided as directive signs, warning signs, prohibitive signs, etc; from the perspective of information state, they can be divided into static type and dynamic ones.

\section{Classification of Public Static Signs in Information State}

The information state embodied in public signs is a decisive factor for choosing and using part of speech in its C-E translation. In the following part, a systematic classification for public signs is presented from the perspective of information state.

\subsection{Static Signs}

Static signs usually deliver information in a static state. It mainly plays directive and serving functions and covers an extensive range of tourist attractions and service, business and sports facilities, culture facilities, healthcare facilities, religious buildings, educational institutions, organizations concerning foreign affairs, names of blocks and streets, etc. There are a great number of these static signs, and their translations are comparatively stable. For instance,

Internet Café; EXP'WAY; One Lane Bridge; International Departure; Taidong Pedestrian Mall; Maintenance Parking

\subsection{Dynamic Signs}

Opposed to the static signs, dynamic signs usually deliver information in a dynamic state. This kind of signs mainly serves to remind the public, compel or forbid them to take some sort of action. Dynamic signs are widely used in public facilities, emergency and the like. Compared with static signs, they are less in number but more flexible in translation.

Arrive; No Photographing; Give Way to Buses; Fasten Seat Belt While Seated 


\section{Functions of Public Signs}

Public signs are pervasive in social life and have an enormous influence on every aspect of people's daily life. According to Ma Jianzhong (2006), public signs, by providing the service of information, meet social, behavioral and psychological demand of the public. Thus public signs can serve six functions as follows.

\subsection{Directing}

First of all, public signs bear the function of directing. They present the information of guiding services without any intention of compelling or restricting. Therefore, they mean offering the content of the service rather than requiring the public to do anything. Take the sign "Car Rental" as an example, it says that a car can be rented from this company or organization. If you need no car, you don't have to do anything. Therefore, the sign aims at offering some reference information to the public, and people may selectively choose to rent a car or not. In More examples of this like:

Toll Gate; Take Away; Baggage Claim; 24-Hour Self-service Bank

\subsection{Prompting}

There is no clear boundary between the function of prompting and that of directing except that the former carries the tone of reminding or warning. The prompting signs aim to call people's considerable attention to the things the signs denote. They are widely used on public occasions. This kind of public sign often adopts brief and euphemistic words and multiform sentence structure. With the information on a public sign, people know how to fulfill a task and it is up to the public to decide whether to carry out the task or not according to the specific situations. For example, "Wet Paint" is often seen near a freshly painted object and it reminds people not to touch the object, or they will be get painted. Here is another example, "Danger Deep Water". When people walk around a deep river or pool, such a sign informs them of the possible danger in case of falling into it. More examples:

Full Booked; Sterilized; Reserved; Maximum Height; Shark Sighted

\subsection{Restricting}

Restricting function is related to constraints and restrictions on readers, usually in a straightforward way, with no offensive or rude intention. In other words, restricting signs confine activities or actions of the related people with their chosen words, but do not imply impolite or rough attitude. This kind of public signs exclusively is applied to a certain group of people. For example,

Keep Right; Staff Only; Handicapped Only; No Entry without a Pass.

\subsection{Compelling}

The function of compelling bears a tougher tone. The compelling signs oblige the related people to take or not to take certain actions in a direct, forceful and tough language. The language of such signs is usually brief and compelling. The sentences are often imperative with negative words like "No", "Forbidden", and so on. In some contexts, people tend to observe the regulation without other choices. For instance,

No Honking; No Fishing Here; Don't Drink and Drive; Police Line Do Not Pass.

\subsection{Advertising}

The public signs serving for an advertising purpose are often seen in stores, supermarkets, trade and exhibition centers, business organizations and pedestrian malls. They can inform or remind existing customers and inform or persuade potential customers about the products or services that are offered. For instance, the sign " $20 \%$ Off" on the windows of a store can attract passersby's attention and make them step into the store to see if there is anything they need.

On Sale; Daily Special; Time-honored Shop; Good to the Last Drop (Maxwell Coffee).

\subsection{Public Interest Publicizing}

Public interest publicizing is an integrated part of humanistic environment in a modern society. By persuading or advocating, it serves as a guide for the public. For example, with the popularization of people's consciousness of environmental protection, it is very common to spot such public signs as "No Economy without Environment" and "Only One Earth". Here are more examples:

Save Water; Yes to Life, No to Drug; Act Now, Save What's Left!; Working Together We Can Make a World of Difference. 


\section{Characteristics of Public Signs}

Public signs belong to a practice variety and have some unique characteristics. They are as follows.

\subsection{Noun Phrases, Verbal Phrases and Gerunds}

As discussed in the first part, public signs, belonging to the static category, usually deliver information in a static state and they mainly play a directive and serving function. Nouns and noun phrases are preferred to show certain information directly and accurately. For example, The Customs; Pet Foods; Food \& Beverage; Guest Lockers. When public signs perform the function of restricting and compelling, they mainly bear a dynamic feature. This kind of public signs is usually composed of verbs, verbal phrases or gerunds. Using verbs, verbal phrase and gerunds can make the language direct, simple and most important of all, powerful, such as Keep Distance; No Admittance; No Overtaking on Bridge; Look Around; Cross Buckle Up.

\subsection{Abbreviated Form}

Among all public signs, those related with public service and public facilities that are most commonly seen and expressed in abbreviations, which makes the signs simple and easy.

ATM; OTC; U Turn OK; 3-D Movies; VIP Suite; IDD

\subsection{Simple Present Tense and Imperative Mood}

Public signs are aimed to convey some kind of message with directive, restrictive, compelling, prompting, or advertising purposes or function to the public in a certain area, so simple present tense is preferred t. For example, Protect Against Heat; Beware Obstruction; Automatic Door Keep Moving.

Imperative mood is applied in public signs to give a compelling force. For example, Do Not Disturb; Keep Off the Grass; Stop on Red; Beware Pedestrians; Please Watch the Steps; Take Care, Not to Leave Things Behind.

\subsection{Absence of Uncommonly-used Words}

Public signs are to the public, including well-educated people and those with little education as well. Thus the use of commonly-seen words or phrases is strongly recommended and uncommonly-used words, slang and jargons should be avoided.

Detour; Fragile; Pay as You Go; Private Parking; Beach Closed; Taxi Picking-up Point.

\subsection{Standardized Usage}

Since public signs play such a significant role in the life of the public, any misinterpretation or misunderstanding will certainly result in negative consequences. Public signs in English, which is closely connected to people's daily life, are expressed in standardized forms and normative expressions that are formed in practical usage for years. The followings are some examples of this sort.

Fitting Room; National Park; Foreign Exchange; Two-Way Traffic; Baggage Depository.

\subsection{Concise Wording}

The wording of public signs is supposed to be compact. Verb tense, nouns, noun phrases and gerunds are especially the top priority. In addition, according to this rule as long as the intended function and meaning of signs are not affected, articles, pronouns, auxiliary verbs and so on can be omitted and thus only content words, core words or key words are used.

Danger!; Road Work; No Left Turn; Passengers Only; Please Pay Driver; Beverage Not Included University Vehicles Only.

\subsection{Capitalized Words}

Generally speaking, in reality most English words in public signs are written in capitalized letters with no full stops, especially those with a small number of words. Language Weekly has generalized the basic rules of capitalizing words in signs: (from www.e-signs.info)

(a) Single-word signs capitalize every word according to international standard: EXIT, ENTRANCE.

(b) As to the names of institutions, capitalize initial letter of each word only:Bank of China.

(c) Ordinal numbers with abbreviated form is used in public sign: 3rd Ring Road.

This generalization may shed light on normalization of capitalizing sign words. But it is still an open question deserving more attention and further discussion. 


\subsection{Combination of Words and Graphic Symbols}

Public signs with striking graphic symbols serve as an effective complement, confirmation and illustration to the written words and turn out to be the best result. The following graphic symbols are excerpted from the signs photographing in Qingdao:
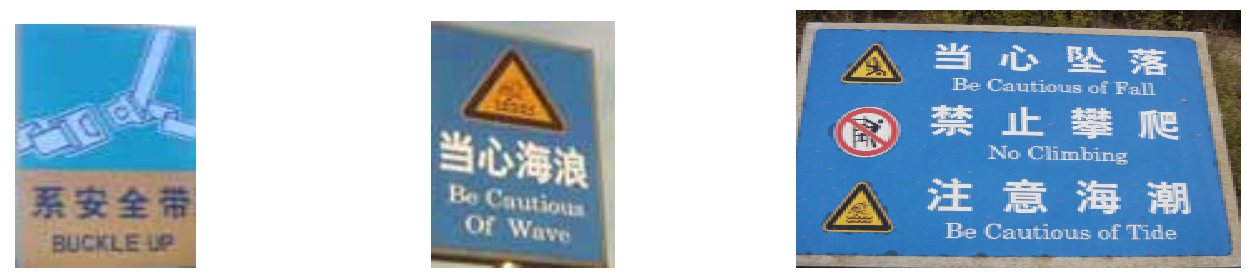

\section{Conclusion}

To sum up, a conclusion can be drawn by analyzing the classification, functions and characteristics of public signs. That is, conciseness, accuracy and target-reader-orientation are the three basic factors in forming and making a public signs. These factors, at the same time, give some hints in translating public signs.

\section{References}

(2003). Oxford Advanced Learner's English-Chinese Dictionary. The Commercial Press.

Eugene A. Nida. (1993). Language, Culture, and Translating. Shanghai: Shanghai Foreign Langue Education Press.

Nida, Eugene A. (1993). The Theory and the Craft of Translation. Approaches to Translation. New York: Pergamon Press. 